\title{
A Systematic Review: The Effective Interventions to Decrease the Occupational Related Diseases in Nurses
}

\author{
$1^{\text {st }}$ Dewi Sartika \\ Nursing Department \\ Health Polytechnic of Riau \\ Pekanbaru, Indonesia \\ tika27asril@gmail.com
}

\author{
$2^{\text {nd }}$ Dewi Irawaty \\ Nursing Faculty \\ University of Indonesia \\ Depok, Indonesia \\ d_irawati@ui.ac.id
}

\author{
$3^{\text {rd }}$ Rusherina \\ Nursing Department \\ Health Polytechnic of Riau \\ Pekanbaru, Indonesia \\ icheriau@yahoo.com
}

\begin{abstract}
Nursing is a profession that focuses on caring for patients individually, family, or community so that the nurses must be able to prevent, maintain, or restore optimal health and quality of life. Rapid and unpredictable health services placed nurses to occupational-related diseases especially musculoskeletal pain, stress, and obesity condition which can increase the risk of cardiovascular diseases. The aim of the systematic review is to examine the literature on the effective interventions to decrease the occupational-related diseases in nurses. This systematic review was carried out by summarizing the preferred reporting items for literature from January 2014 to June 2019, which produced five articles. The articles were accessed from the internet search engine database; Proquest, EBSCO, and Science Direct. From the five articles reviewed, it was found that three interventions to reduce the occupationalrelated diseases: physical exercise at work, stress management, nutrition and exercise programs in Health education. In conclusion, this review show that single and combination interventions do indeed decrease stress, musculoskeletal pain, and risk of cardiovascular diseases in nurses. However, there is a need for stronger methodological studies to define the most effective and sustainable interventions for each occupationalrelated disease.
\end{abstract}

Keywords: nurse, systematic review, occupational related diseases

\section{INTRODUCTION}

Nurses as one of the health workers who provide 24hours services must improve the services to provide quality of services [5]. As a profession, nursing focuses on caring for patients individually, family, or community so that the nurses must be able to prevent, maintain, or restore optimal health and quality of life. Fast and unpredictable health services place nurses to occupational-related diseases such as high work stress [12]. Occupational-related stress was more experienced by nurses than other health workers [1]. Study results showed that the overall level of occupationalrelated stress was $58.46 \pm 12.62$. The highest level of stress related to death with an average score of $62.94 \%$, then followed by uncertainty regarding patient care $57.72 \%$, workload $57.6 \%$, and sexual harassment of $46.19 \%$ [3]. Non-communicable diseases related to stress that became the world health crisis in the 21 st century, namely coronary artery disease, diabetes, chronic lung and GI diseases, cancer, neuropsychiatric disease (NPD), and arthritis. [11] American Nurses Association (ANA) stated that nurses who work in teams need to pay attention to their health and safety because, at work, nurses are at risk of injury and illness because of their work. ANA's survey results in 2011 showed that the amount of back, neck and shoulder pain in nurses continued to increase [2]. Furthermore, the results of the study [4] showed that because of their work, nurses experienced neck pain by $26 \%$, cervical pain by $16.7 \%$, upper back pain by $40 \%$ and lower back pain by $33 \%$.

In Indonesia, several studies have shown that nurses experience several work-related diseases that have the potential to reduce nurse performance in nursing service. Some diseases that can arise in nurses due to work were respiratory diseases, hypertension, digestive tract and other complaints such as earaches, headaches, urinary disorders, disorders during pregnancy, skin diseases and musculoskeletal disorders. [7]

Various work-related diseases if there is no concern there will be an increase in absenteeism, decrease job satisfaction, decrease productivity, loss of self-confidence, creativity, and concentration of nurses in work. The negative consequences of poor health and safety conditions for nurses were absenteeism, decrease hospital income, decrease productivity and increase medical errors. [9, 13,

Several studies have found interventions to decrease occupational-related diseases, but none have reported them in the form of systematic reviews of interventions that were effective or success at reducing occupational-related diseases among nurses especially the diseases that were experienced by many nurses namely musculoskeletal pain, stress and obesity 
which can increase the risk of cardiovascular disease. Therefore, this systematic review was carried out with the purpose of examining the literature on the effective interventions to decrease the occupational-related diseases in nurses.

\section{METHODOLOGY}

A systematic search for studies relating to the successful interventions to decrease the occupational-related diseases was carried out using PRISMA design and the following steps: 1) Defining the research questions; "What are the effective interventions for decreasing occupational-related diseases in nurses", 2) Identifying variables using PICO (Population: nurses, Intervention: the effective interventions, Compare: -, Output: decreasing work-related diseases), 3)Identify literature with available search engines (Proquest, EBSCO, and Science Direct) based on keywords; nurses, the effective interventions, and occupational-related diseases, 4)Filter the literature with inclusion criteria; full text, year: January 2014 - June 2019, language: English, document type: article, and design: intervention study, 5)Assess the article: available and complete abstract text; eligibility, 6)Compiling articles using the Reference Manager application, 7) Combining and presenting the results using a data extraction table. The flowchart of publication selection as follow in figure 1:

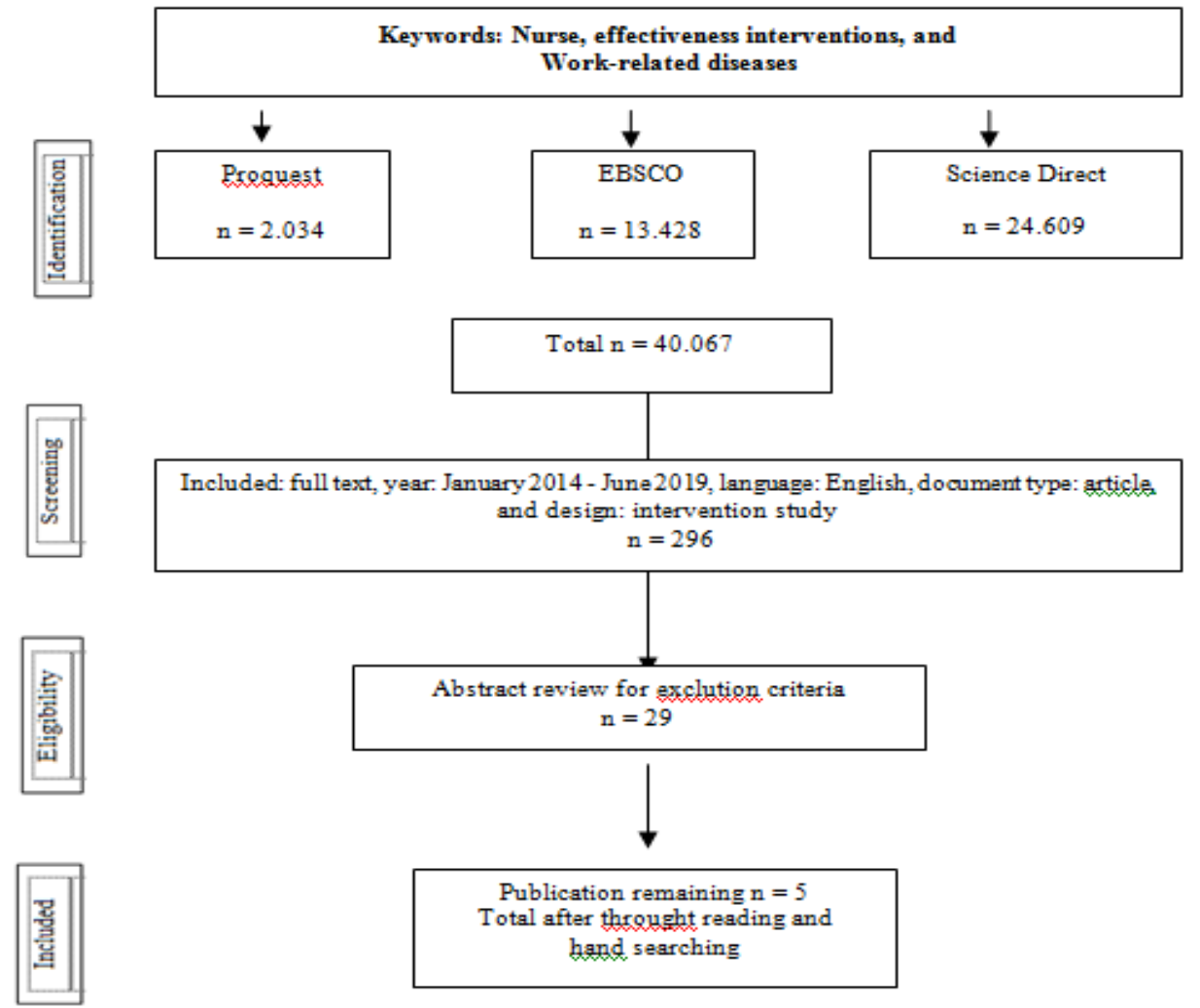

Figure 1. Publication Selection Flow Chart

\section{FINDINGS AND DISCUSSION}

After an initial screening, many articles were eliminated for not meeting the inclusion criteria. The remaining articles were examined by a repeated reviewed by abstract and full text obtained five articles for further review. Decent research consists of several studies conducted in various countries. Analysis of the five articles showed that four articles with Randomized Controlled Trial (RCT) design, and one article with quasy-experiment design.

Extraction of this data was conducted by analyzing the data based on the author's name, interventions, and results or effect on reduce work-related diseases, namely grouping important data in the article. As for data extraction results can be seen in table 1 . 
TABLE 1. DATA EXTRACTION

\begin{tabular}{|l|l|l|}
\hline \multicolumn{3}{|c|}{ TABLE 1. DATA EXTRACTION } \\
\hline $\begin{array}{l}\text { Researchers } \\
(2019)\end{array}$ & $\begin{array}{l}\text { Intervention } \\
\text { Multicomponent } \\
\text { intervention: } \\
\text { ergonomics, case } \\
\text { management and health } \\
\text { promotion }\end{array}$ & $\begin{array}{l}\text { Decrease musculoskeletal } \\
\text { pain and sickness absence }\end{array}$ \\
\hline $\begin{array}{l}\text { Jakobsen et al. } \\
(2017)\end{array}$ & $\begin{array}{l}\text { Group-based workplace } \\
\text { physical exercise }\end{array}$ & $\begin{array}{l}\text { Improve ancern and vitality, } \\
\text { control } \\
\text { musculoskeletal pain }\end{array}$ \\
\hline $\begin{array}{l}\text { Matsugaki et al. } \\
(2017)\end{array}$ & $\begin{array}{l}\text { Workplace exercise } \\
\text { supervised by a } \\
\text { physical therapist }\end{array}$ & $\begin{array}{l}\text { Improve muscle strength, } \\
\text { lipoprotein cholesterol, } \\
\text { metabolic profile and } \\
\text { depressive } \\
\text { symptom }\end{array}$ \\
\hline $\begin{array}{l}\text { Imamura et al. } \\
(2019)\end{array}$ & $\begin{array}{l}\text { Multimodule } \\
\text { stress management } \\
\text { programme }\end{array}$ & $\begin{array}{l}\text { Decrease apressive and anxiety } \\
\text { symptoms, and work } \\
\text { performance }\end{array}$ \\
\hline Tsai et al. (2015) & $\begin{array}{l}\text { e-health } \\
\text { exercise, nutrition }\end{array}$ & $\begin{array}{l}\text { Decrease BMI, increase } \\
\text { physic and mental } \\
\text { component summary }\end{array}$ \\
\hline
\end{tabular}

Serra et al. [14] conducted their research to assess the effectiveness of multi-component interventions to prevent and manage Musculoskeletal Pain (MSP) in staff of nursing in the workplace. This research was carried out by Randomized Control Trial (RCT) to intervent and the control group. The respondents of this research were nurses and nursing assistants. Evidence-based multi-component interventions were designed to combine participatory ergonomics, case management, and health promotion. Both of the intervention and control groups received occupational health care as usual. Data were collected at the beginning of the research, and after six and 12 months the intervention was carried out. The main results of this research were the incidence of MSP and the incidence and duration of absences caused by MSP. Then the secondary outcomes were the function of the work role and the preventive culture of the organization. Economic evaluations include costeffectiveness and cost-utility, calculated from the perspective of the community and the National Health System. Serra et al. stated that workplace health programs were one of the best choices for the prevention and control of noncommunicable diseases. The main characteristics of this study were the existence of multidisciplinary interventions, and de-medicalization, which includes three evidence-based interventions and includes three levels of prevention, which were not previously united in one single intervention. In addition, evaluations of the intervention process, health outcomes, and economic impacts were carried out in a comprehensive quantitative and qualitative manner. This research can open up new paradigms for MSP prevention and management and approaches for the absence of occupational-related diseases.

Jacobsen et al. [8] conducted their research of the psychosocial benefits of physical exercise at work. Performed by the RCT Method on 200 female health workers (including nurses) from 18 departments in three hospitals. The selection of respondents was carried out by random allocation at the cluster level for ten weeks.

The interventions include: 1) home-based physical exercise, which was done alone during leisure time for ten minutes five days per week, 2) physical exercise at work, which was carried out in groups during working hours for ten minutes five days per week and up to five group-based training sessions on motivation for regular physical exercise. Variables assessed at baseline and follow-up after ten weeks of intervention were vitality and mental health, psychosocial work environment, work disability and recreation, concern and control about each pain using predetermined instruments. The results showed that doing physical exercise at the same time with group during working time attended by training adherence showed the higher result and more effective than home-based training in increasing vitality, concern, and pain control of nurses. Therefore, group-based workplace interventions aimed at pain relief can encourage benefits both physiologically and psychosocially.

Matsugaki et al. [10] conducted their research to assess the effectiveness of supervised exercise to 30 female nurses who do shift work. Female nurses were randomized and divided into two groups, namely: 1) Supervised exercise groups (SG; nurses exercising under the supervision of a physical therapist), and 2) Voluntary training groups (VG; nurses exercising without supervision). Nurses in this study were asked to exercise twice a week for 12 weeks for 24 sessions. The main outcome assessed was aerobic fitness and secondary outcomes were muscle strength, anthropometric data, biochemical parameters, and mental health. The researcher compared all outcomes assessed before and after the intervention in each group and between the two groups. Aerobic fitness improved in SG while VG reduced, but this change was not statistically significant. However, the differences between groups were significant in the effect of the intervention. Muscle strength, highdensity lipoprotein cholesterol and metabolic profile (high molecular weight adiponectin), and depressive symptoms showed the significant symptoms in SG over time, although SG lacks exercise compared to 
VG. In addition, significant differences in muscle strength, and low-density lipoprotein cholesterol and reactive oxygen metabolite levels were observed between the two groups and these parameters were better in SG than in VG. It can be concluded that the results of this research indicate that effective training was the exercise that is supervised by a physical therapist at work for nurses who do shift work in terms of health promotion.

Imamura et al. [6] in their research of the effects of two types of stress management programs based on smartphones on the variation of depression and conflict among hospital nurses. The target population of this study was registered nurses working in public hospitals in Vietnam. Nurses who agreed to the eligibility criteria for the study were allocated to participate in stress management interventions in the form of multi modules and cognitive therapy via the internet (i.e. CBT) of 360 registered nurses. While the control group that followed the stress management intervention as usual also numbered 360 registered nurses. There are two types of choices from six smartphone-based module stress management programs. Nurses in the group completed one of the programs within ten weeks after the initial survey. The main outcome assessed was depression and conflict, using the Depression Anxiety and Stress Scales (DASS) instrument measured at three months and seven months of follow-up. The most power of this research was its emphasis on the effects of a webbased smartphone application intervention program that automatically supports stress management and reduces symptoms of depression and anxiety. This research added to evidence of the effect of the e-stress management program on positive outcome namely on participation and nurse's performance Tsai et al. [15] conducted their research to evaluate the effect of health promotion on Health interventions among nurses compared to conventional learning handbooks. The research was conducted on 105 nurses, 55 in the experimental group and 60 in the control group, for three months of intervention. Both groups completed questionnaires before and after the intervention of the Lifestyle Profile that Improved Health and Short-Form Health Survey. The eHealth intervention contains two pages of links, namely: 1) Online news: researchers provide local and foreign online news related to daily health problems and 2) health-related websites, including sports and healthy diet/nutrition sites. Then, the group completed the questionnaire before and after the intervention of health promotion about a healthy lifestyle. The results recorded were height, weight, and body mass index. Health educational interventions have the effect of increasing significantly the total post-intervention nurses who follow the intervention.
No significant changes were observed in the postintervention score of the control group subjects. The experimental group also experienced a significant decrease in BMI after the intervention, but no similar changes were observed in the control group. From the results, Tsai et al. concluded that eHealth education is an effective and easily reachable intervention to improve nurses's health promotion behavior to reduce occupationalrelated illnesses, obesity which can increase the risk of cardiovascular disease.

The association between the intervention variable and the effect variable on occupational-related diseases found in this systematic review have passed an adequate theoretical study and the results obtained were generally supported also by the results of research in the previous year which also showed the same results. In general, this systematic review found three main interventions in reducing musculoskeletal pain, stress and obesity as the risk of cardiovascular diseases in the form of physical exercise, stress management and healthy diet which are generally carried out not singly but rather a combination intervention, because between pain, stress, and actual obesity there are links to non-communicable diseases. Then there was two forms of intervention in broad outline, namely based on information technology (eHealth education) and not based on information technology.

For musculoskeletal pain, based on this systematic review, interventions that can be carried out were Multicomponent Interventions related to ergonomics, Group-based workplace physical exercise, Workplace exercise supervised by a physical therapist, and eHealth education related to exercise. The emphasis on these interventions was done in groups to further improve motivation and social relations among nurses in the hospital, supervised by experts (Physical Therapist) to be more effective and more practical if based on eHealth education.

For stress, interventions that can be carried out were exercise supervised by a physical therapist and the multimodule stress management program. The emphasis on these interventions was also supervised by experts to be more effective and more practical if based on eHealth.

Then for obesity as a disease that can increase the risk of cardiovascular diseases, based on this systematic review, interventions that can be carried out were eHealth education included exercise and nutrition, and Workplace exercise supervised by a physical therapist. As with stress interventions, the emphasis on these interventions is also supervised by experts to be more effective and will be more practical if based on eHealth. 


\section{IMPLICATION FOR PRACTICE}

The results of the studies in this systematic review are very important because they have a very significant impact especially on nurses and policymakers or decisions in hospitals. Interventions that have been declared effective in reducing occupational-related diseases are possible to be applied in nursing practice in Indonesia because in several articles that have been discussed there are similarities in the problems experienced by nurses. Intervention programs that use technology (eHealth) also need to be considered to be implemented in the context of era 5.0. The implication for nurses is that nurses can follow intervention programs to decrease occupational-related diseases experienced by that nurses. Of course, this is inseparable from the commitment and role of hospital management that organizes the intervention program. The implication for policymakers or decisions in hospitals, in this case the management is to have a high commitment to organize and facilitate intervention programs in accordance with the most frequent problems and occupational-related diseases experienced by nurses who interfere in the provision of nursing services, so that by reducing the health problems experienced by nurses, quality nursing services can be provided to patients.

\section{STRENGHT AND LIMITATION}

This systematic review has strength and limitation. It strength lies in the discovery of interventions that have been proven effective in overcoming nurses' problems to decrease occupational-related diseases with a fairly new academic year (2015-2019). But this systematic review also has limitations, where researchers only found 4 out of 5 articles that have RCT designs which certainly have high internal and external validity. Another limitation is that it is difficult to find articles according to establishes criteria that discuss single intervention on a single effect, so it is quite difficult to distinguish the effects of an intervention for one type of occupational-related diseases.

\section{CONCLUSIONS}

Of the five articles reviewed, it was found that there are three interventions to decrease occupational-related diseases namely: physical exercise at work, stress management, nutrition and exercise programs in the form of eHealth. This systematic review showed that single and combination interventions indeed reduce stress, musculoskeletal pain, and obesity as one of the risks of cardiovascular disease among nurses. The emphasis on interventions that are declared effective is these interventions was done in groups (for physical exercise) to further improve motivation and social relations among nurses in the hospital. Then the intervention supervised by experts (Physical Therapist) to be more effective. The other emphasis is the intervention is more practical if it is based on technology (eHealth). Based on the limitations of this systematic review, going forward, stronger methodological studies are needed to define the most effective and sustainable interventions for each type of occupational-related disease.

\section{REFERENCES}

[1] Almajwal, A. M., "Stress, shift duty, and eating behavior among nurses in Central Saudi Arabia," in Saudi Medical Journal, ProQuest, 2016, 37(2), 191-198. [Online]. Available: https://doi.org/10.15537/smj.2016.2.13060.

[2] American Nurses Association. 2017. 2017 Year of the Healthy Nurse. [Online]. Available: https://doi.org/10.1097/01.NPR.0000515822.62607.a8.

[3] Dagget, T., Molla, A., \& Belachew, T., "Job related stress among nurses working in Jimma Zone public hospitals, South West Ethiopia : a cross sectional study," BMC Nursing, Google Shcolar, 2016, 1-10. [Online]. Available: https://doi.org/10.1186/s12912-0160158-2.

[4] Freitas-swerts, F. C. T. De, "The effects of compensatory workplace exercises to reduce work-related stress and musculoskeletal pain," in Rev. Latino-Am.Enfermagem, Google Shcolar, 2014, 22(4), 629-636. [Online]. Available: https://doi.org/10.1590/0104-1169.3222.2461.

[5] Hariyati. Planning for the development and utilization of nursing staff.

Jakarta: PT Raja Grafindo Persada, 2014.

[6] Imamura, K. et al., "Effects of two types of smartphone based stress management programmes on depressive and anxiety symptoms among hospital nurses in Vietnam: a pro mtocol for three-arm randomized controlled trial," in BMJ Open, ProQuest, 2019, 9:e025138. [Online]. Available: https://doi.org/10.1136/bmjopen2018-025138.

[7] Isnaniar. "The relationship between human factors, the environment, occupational safety and health management with occupational diseases and accidents in nurses in hospitalization I Arifin Achmad Hospital, Pekanbaru,". E-skripsi Universitas Andalas. 2017.

[8] Jakobsen et al., "Psychosocial benefits of workplace physical exercise:

Cluster randomized controlled trial," in BMC Public Health, ProQuest, 2017, $17 \quad$ (1). [Online]. Available: https://doi.org/10.1186/s12889-0174728-3.

[9] Mahdasari, M., Handiyani, H., \& Pujasari, H., “ Improvement of nurses' self safety through optimization of management functions," in Jurnal Keperawatan Indonesia, JKI, 2016, 19 (3), 176-183. [Online]. Available: https://doi.org/10.7454/jki.v19i3.472.

[10] Matsukagi et al., "Effectiveness of workplace exercise supervised by a physical therapist among nurses conducting shift work: A randomized controlled trial," in J Occup Health, EBSCOhost, 2017; 59: 327-335.

[Online]. Available: https://doi.org/10.1539/joh.16-0125-OA.

[11] Narayan, K.M, Ali, M.K, \& Koplan, J.P, "Global non-communicable diseases-where worlds meet," in N Engl J Med, Google Shcolar, 2010, 363 (13), 1196-98.

[12] Nippanon, P., Kwasu, N., \& Keow, T., "Healthy Exercise of Registered Female Nurses in Khon Kaen," in Procedia - Social and Behavioral Sciences, ScienceDirect, 2017, 237, 137-143. [Online]. Available: https://doi.org/10.1186/s12889-019-6683-7. 
[13] Palumbo, M.V., Mclaughlin, V., Mcintosh, B., \& Rambur, B.,

"Practical nurses' health and safety in nursing homes,",in Nursing Research, PubMed, 2011. [Online]. Available: https://www.ncbi.n lm.nih.gov/pubmed/22359843.

[14] Serra et al., "Prevention and management of musculoskeletal pain in nursing staff by a multifaceted intervention in the workplace: design of a cluster randomized controlled trial with effectiveness, process and economic evaluation (INTEVAL_Spain)", in BMC Public Health, ProQuest, 2019, 19 (348). [Online]. Available: https://doi.org/10.1186/s12889-019-6683-7.

[15] Tsai et al., "An eHealth education intervention to promote healthy lifestyles among nurses," in Nurs Outlook, ScienceDirect, 2015, 63, 245-254. [Online]. Available:

https://doi.org/10.1016/j.outlook.2014.11.005. 